\title{
A PARTICIPAÇÃO DA CRIANÇA DESDE A PRIMEIRA INFÂNCIA NAS AÇÕES QUE VISEM ENFRENTAR A VIOLENCIA INTRAFAMILIAR E SUAS CONSEQUÊNCIAS COMO UMA ESTRATÉGIA FUNDAMENTAL PARA A CONSTRUÇÃO DE UMA POLÍTICA EFETIVA
}

\author{
$*$ \\ Rosane Teresinha Carvalho Porto \\ Universidade de Santa Cruz do Sul - UNISC - Brasil \\ Fabiano Rodrigo Dupont \\ Universidade de Santa Cruz do Sul - UNISC - Brasil
}

\section{Resumo}

O presente artigo tem por finalidade analisar a lei 13.257, de 08 de março de 2016 que dispõe sobre as políticas públicas para a primeira infância com base no Plano Nacional Pela Primeira Infância, em que propõe ações amplas e articuladas de promoção e realização dos direitos da criança de até seis anos de idade nos próximos doze anos. Dentre os seus mais diversos objetivos e metas de proteção integral a família está a participação da criança desde a primeira infância nas ações que visem enfrentar a violência intrafamiliar e suas consequências como uma estratégia fundamental para a construção de uma política efetiva. Como mecanismos de construção do texto utilizou-se o método de abordagem o hipotético-dedutivo, como método de procedimento o monográfico e a técnica de revisão bibliográfica.

Palavras-chave: criança e adolescente, violência intrafamiliar, gênero.

\section{Introdução}

A lei $\mathrm{n}^{\circ} 13.257$, de 08 de março de 2016 é uma legislação sob a perspectiva de gênero que contempla a perspectiva de gênero, a partir da intersetorialidade e da multidisciplinariedade com a finalidade de trabalhar a dimensão complexa dos sujeitos de direitos. Para prestigiar a criança e escutá-la, estimulando a sua participação e cotejando a sua proteção dentro da família, a rede também precisa ser construída dentro dos espaços escolares, sendo lá o espaço propício para o seu protagonismo.

No contexto brasileiro, as crianças são consideradas portadoras de direitos e de deveres, como bem reza a Constituição Federal de 1988 e o Estatuto da Criança e do Adolescente, porém, são necessárias políticas públicas efetivas, no sentido de enfrentar a violação desestruturante da personalidade que causa a violência estrutural.

A participação da criança desde a primeira infância nas ações que visem enfrentar a violência intrafamiliar e suas consequências é uma estratégia fundamental para a construção 
de uma política efetiva. Essa participação deve ocorrer nas relações de convivência familiar e comunitária, como também nas políticas públicas e nos programas oficiais. A participação começa no escutar e levar em consideração as opiniões e desejos da criança.

Por isso, no referido artigo de pesquisa tratar-se-á especificadamente das alterações decorrentes da lei que dispõe sobre as políticas públicas para a primeira infância, no Estatuto da Criança e do Adolescente. A partir disso, conduzir-se-á o debate para as ações propostas pelo legislador para o enfrentamento violência intrafamiliar e suas consequências.

\section{O MARCO LEGAL DAS POLÍTICAS PÚBLICAS PARA A PRIMEIRA INFÂNCIA: LEI N'13.257, DE 08 DE MARÇO DE 2016}

A Lei n 13.257, de 08 de março de 2016 é significativa por reconhecer a necessidade de se pensar e efetivar políticas públicas de proteção e atendimento as crianças nos seus primeiros anos de vida. O legislador demonstra reconhecer acertadamente que esta fase é fundamental para a formação de um cidadão. Interessante ainda mencionar, que esta legislação trouxe alterações no Estatuto da Criança e do Adolescente, nas leis trabalhistas com a questão do direito a paternidade e no Código de Processo Penal, possibilitando à mãe ou o pai a prisão domiciliar, caso sejam os únicos responsáveis pela criança ${ }^{1}$.

Historicamente, a criança e o adolescente, principalmente aqueles oriundos das classes mais baixas da população, foram submetidos a tratamento desumano, escravizados, reprimidos, controlados, abandonados, encarcerados, criminalizados, utilizados como mão de obra barata e dócil, enfim, tiveram a infância roubada e destruída em nome da criação de um

\footnotetext{
${ }^{1}$ Art. 41. Os arts. 6o, 185, 304 e 318 do Decreto-Lei no 3.689, de 3 de outubro de 1941 (Código de Processo Penal), passam a vigorar com as seguintes alterações:

"Art. 60

$\mathrm{X}$ - colher informações sobre a existência de filhos, respectivas idades e se possuem alguma deficiência e o nome e o contato de eventual responsável pelos cuidados dos filhos, indicado pela pessoa presa." (NR)

“Art. 185.

$\S$ 10. Do interrogatório deverá constar a informação sobre a existência de filhos, respectivas idades e se possuem alguma deficiência e o nome e o contato de eventual responsável pelos cuidados dos filhos, indicado pela pessoa presa." (NR)

"Art. 304.
}

§ 4o Da lavratura do auto de prisão em flagrante deverá constar a informação sobre a existência de filhos, respectivas idades e se possuem alguma deficiência e o nome e o contato de eventual responsável pelos cuidados dos filhos, indicado pela pessoa presa." (NR)

"Art. 318.

IV - gestante;

V - mulher com filho de até 12 (doze) anos de idade incompletos;

VI - homem, caso seja o único responsável pelos cuidados do filho de até 12 (doze) anos de idade incompletos. ." (NR)

Barbarói, Santa Cruz do Sul, Edição Especial n.47, p.<179-192>, jan./jun. 2016 
"novo projeto de civilização". Para eles, no Brasil, foi instituída a doutrina da situação irregular, política baseada no direito penal do menor, que variava do assistencialismo à total segregação. Crianças e adolescentes passaram a ser objeto de tutela do Estado que, com a justificativa de estar ajudando as famílias pobres na educação de seus filhos, cria abrigos e internatos, lugar onde ocorrem as mais terríveis transgressões dos direitos humanos.

A violência contra a criança e o adolescente não ocorre apenas no Brasil, é um fenômeno global, embora as violações de seus direitos sejam mais acentuadas em países pobres, nos quais é grande a exploração do trabalho e da pornografia infantil, por exemplo. A ideia de reconhecer a proteção especial para a criança e o adolescente também não é nova. $\mathrm{O}$ princípio da proteção integral previsto na legislação estatutária também se estende a legislação da primeira infância responsável pela alteração e redirecionamento de políticas para esta fase do desenvolvimento humano.

Sendo assim, A lei 13.257, de 08 de março de 2016 dispõe sobre as políticas públicas para a primeira infância ${ }^{2}$ com base no Plano Nacional Pela Primeira Infância, que propõe ações amplas e articuladas de promoção e realização dos direitos da criança de até seis anos de idade nos próximos doze anos. Dentre os seus mais diversos objetivos e metas de proteção integral a família está a participação da criança desde a primeira infância nas ações que visem enfrentar a violência intrafamiliar e suas consequências como uma estratégia fundamental para a construção de uma política efetiva.

Quando se trata de direitos humanos, estabelece-se uma relação entre esses sujeitos de direitos e os responsáveis por assegurá-los - a família, o Estado e a sociedade. Apesar de a legislação brasileira ser uma das mais avançadas no mundo em relação à proteção das crianças (Constituição Federal e Estatuto da Criança e do Adolescente, bem como os tratados internacionais dos quais o Brasil é signatário), as leis que expressam essa proteção não estão efetivadas no cotidiano de uma parcela significativa da população infanto-adolescente.

A violência intrafamiliar constitui a maior parte dos registros de violência contra a criança, representa a primeira causa de morte de crianças de um a seis anos no Brasil. Cerca

\footnotetext{
${ }^{2}$ Art. 1o Esta Lei estabelece princípios e diretrizes para a formulação e a implementação de políticas públicas para a primeira infância em atenção à especificidade e à relevância dos primeiros anos de vida no desenvolvimento infantil e no desenvolvimento do ser humano, em consonância com os princípios e diretrizes da Lei no 8.069, de 13 de julho de 1990 (Estatuto da Criança e do Adolescente); altera a Lei no 8.069, de 13 de julho de 1990 (Estatuto da Criança e do Adolescente); altera os arts. 6o, 185, 304 e 318 do Decreto-Lei no 3.689, de 3 de outubro de 1941 (Código de Processo Penal); acrescenta incisos ao art. 473 da Consolidação das Leis do Trabalho (CLT), aprovada pelo Decreto-Lei no 5.452, de 1o de maio de 1943; altera os arts. 1o, 3o, 4o e 5o da Lei no 11.770, de 9 de setembro de 2008; e acrescenta parágrafos ao art. 5 o da Lei no 12.662, de 5 de junho de 2012.
} 
de 200 mil crianças e adolescentes declararam ter sofrido agressão física e, em $80 \%$ dos casos, os autores de violência eram parentes e conhecidos ${ }^{3}$.

No mesmo sentido tem-se o artigo $5^{\circ}$ do Estatuto da Criança e do Adolescente (Lei 8069/90) ao afirmar que: Nenhuma criança ou adolescente será objeto de qualquer forma de negligência, discriminação, exploração, violência, crueldade e opressão, punido na forma da lei qualquer atentado, por ação ou omissão, aos seus direitos fundamentais.

O referido dispositivo legal, portanto, exige mecanismos específicos para que a criança e o adolescente permaneçam a salvo de todo o tipo de violência. E é somente através de políticas públicas, aplicadas tanto pelo Estado como pela sociedade, ou seja, serviços especiais de prevenção e atendimento psicossocial às vítimas de negligência, maus-tratos, exploração, abuso, crueldade e opressão que se poderão obter os resultados desejados nos termos dos artigos 86 e 87, III, desta lei.

No artigo $4^{\circ}$ da Lei 13.257 de 2016 as políticas públicas voltadas ao atendimento dos direitos da criança na primeira infância serão elaboradas e executadas de forma a atender ao interesse da criança e à condição de sujeitos de direitos ${ }^{4}$.

A participação da criança desde a primeira infância nas ações que visem enfrentar a violência intrafamiliar e suas consequências é uma estratégia fundamental para a construção de uma política efetiva. Essa participação deve ocorrer nas relações de convivência familiar e comunitária, como também nas políticas públicas e nos programas oficiais. A participação começa no escutar e levar em consideração as opiniões e desejos da criança principalmente no núcleo familiar.

\section{A VIOLÊNCIA INTRAFAMILIAR E SUAS CONSEQUÊNCIAS SOCIOJURÍDICAS}

\footnotetext{
${ }^{3}$ Segundo o livro Impacto da Violência na Saúde dos Brasileiros (2005), publicado pela Secretaria de Vigilância em Saúde, do Ministério da Saúde. (UNICEF, 2005, p. 22).

${ }^{4}$ I - atender ao interesse superior da criança e à sua condição de sujeito de direitos e de cidadã;

II - incluir a participação da criança na definição das ações que lhe digam respeito, em conformidade com suas características etárias e de desenvolvimento;

III - respeitar a individualidade e os ritmos de desenvolvimento das crianças e valorizar a diversidade da infância brasileira, assim como as diferenças entre as crianças em seus contextos sociais e culturais;

IV - reduzir as desigualdades no acesso aos bens e serviços que atendam aos direitos da criança na primeira infância, priorizando o investimento público na promoção da justiça social, da equidade e da inclusão sem discriminação da criança;

$\mathrm{V}$ - articular as dimensões ética, humanista e política da criança cidadã com as evidências científicas e a prática profissional no atendimento da primeira infância;

VI - adotar abordagem participativa, envolvendo a sociedade, por meio de suas organizações representativas, os profissionais, os pais e as crianças, no aprimoramento da qualidade das ações e na garantia da oferta dos serviços;
} 
Nos últimos anos, tem-se divulgado de forma eloquente a imagem de crianças e adolescentes, isso devido a uma situação mais de lamento do que por outro motivo. As condições a que estão submetidas as crianças e adolescentes vieram à tona, tornou-se público. Excluídos dos objetivos políticos e econômicos do país, são levados a se deixarem explorar, violar, sem qualquer restrição.

A violência doméstica pode ser definida como sendo:

\begin{abstract}
todo ato ou omissão, praticado por pais, parentes ou responsáveis contra crianças e/ou adolescentes que, sendo capaz de causar dano físico, sexual e/ou psicológico à vítima, implica numa transgressão do poder/dever de proteção do adulto e, por outro lado, numa coisificação da infância, isto é, numa negação do direito que crianças e adolescentes têm de ser tratados como sujeitos e pessoas em condição peculiar de desenvolvimento. (AZEVEDO E GUERRA, 2001)
\end{abstract}

As crianças e adolescentes, durante muito tempo, permaneceram à margem dos interesses sociais e das expectativas para a concretização de seus direitos. Apesar dos movimentos e das conquistas sociais em prol da defesa e efetivação dos direitos humanos. Afinal, a codificação de seus direitos, por mais expressiva, não representou a real solução para os problemas vivenciados, vez que entre o texto legal e a realidade social ainda há um enorme distanciamento.

A violência doméstica e a privação familiar são as causas que mais contribuem para a formação de comportamentos tidos como desviantes e, consequentemente, para o aumento e a perpetuação da violência. Todo programa de combate à violência será incompleto e ineficaz se continuar priorizando medidas restritivas e punitivas, descuidando das medidas preventivas, as mais importantes. Com base no artigo 227 da Carta Política em combinação com os artigos $1^{\circ}$ e $3^{\circ}$, tem-se o princípio da prioridade absoluta, vinculado a teoria da proteção integral. Além disso, também estão previstos os direitos especiais de proteção, regulamentos pela legislação estatutária, no seu artigo $5^{\circ}$. Segundo o autor: "o reconhecimento dos direito fundamentais à criança e ao adolescente trouxe consigo o princípio da universalização, segundo o qual os direitos catalogado são suscetíveis de reinvindicação e efetivação para todas as crianças e os adolescentes". De igual modo, "o Direito da Criança e do Adolescente emerge como um sistema orientado pelo princípio do interesse superior da criança, previsto no artigo $3^{\circ}, 1$, da Convenção Internacional sobre os Direitos da Criança",5.

O princípio da ênfase nas políticas públicas sociais básicas visa promover o reordenamento institucional, provendo um conjunto de serviços de efetivo atendimento às necessidades de crianças, adolescentes e suas próprias famílias por meio de políticas de

\footnotetext{
${ }^{5}$ CUSTÓDIO, André Viana. Direito da Criança e do Adolescente. Criciúma, SC: UNESC, 2009, p. 40.
} 
promoção e defesa dos direitos. Com efeito, a universalização dos serviços públicos através das políticas sociais básicas, impõe a implementação de verdadeiras redes de atendimento à população. Assim, a implementação das políticas públicas requer o respeito ao princípio da descentralização político-administrativa, pois estas políticas devem ser realizadas no lugar onde vivem as pessoas, conforme estabelece no artigo 86 da legislação estatutária .

Sob esse prisma ainda de maneira exemplificativa tem-se o princípio da participação popular na construção das políticas públicas articuladas entre a sociedade civil e o Estado, com a atuação dos Conselhos dos Direitos da Criança e do Adolescente. Menciona-se ainda a desjurisdicionalização e princípio da despoliciação, que não esgotam a riqueza principiológica que alude o Direito da Criança e do Adolescente, conforme o artigo 100 da legislação estatutária.

Configura-se na obra de Viana os direitos fundamentais da criança e do adolescente a partir do artigo 227 da Constituição Federal de 1988 em consonância com a legislação estatutária (o direito à vida e a saúde de crianças e adolescentes, o direito à liberdade, ao respeito e à dignidade, o direito à convivência familiar e comunitária, o direito à educação, à cultura, ao esporte e ao lazer, e o direito à proteção no trabalho). Sob a perspectiva dos direitos fundamentais é possível (re)pensar no sistema de garantias de direitos vinculado a política de prevenção primária, secundária e terciária voltada aos interesses da criança e do adolescente. Interessante a explicação do autor a respeito do tema: “ O Estatuto da Criança e do Adolescente destinou segmento específico para tratar da prevenção contra violação dos direitos de crianças e adolescentes. Não se pode confundi-las com a ideia de prevenção contra atitudes de crianças e adolescentes, mas em efetiva proteção contra a violação de seus direitos". Por isso a relevância em observar e aplicar o artigo 70 e seguintes da legislação estatutária ${ }^{6}$.

Existem direitos que são destacáveis da pessoa humana, como a propriedade, e outros que são inerentes, ligados à pessoa humana de modo permanente. São os denominados direitos de personalidade, incluindo-se a vida, a liberdade física e intelectual, o nome, o corpo, a imagem e aquilo que crê como honra. O Estatuto prefere falar em dignidade, não deixando, contudo de se referir ao tratamento condigno que se espera dos outros. Tal expressão é utilizada no Código Penal denominada crimes contra a dignidade sexual.

Sendo assim, os direitos de personalidade são inalienáveis, intransmissíveis, imprescritíveis e irrenunciáveis. Tais características são previstas no Código Civil, que em seu

\footnotetext{
${ }^{6}$ CUSTÓDIO, André Viana. Direito da Criança e do Adolescente. Criciúma, SC: UNESC, 2009, p. 40. 
artigo 11 menciona que "os direitos da personalidade são intransmissíveis e irrenunciáveis, não podendo o seu exercício sofrer limitação voluntária”. Assim, além dos direitos fundamentais da pessoa humana, gozam a criança e o adolescente do direito subjetivo de desenvolvimento físico, mental, moral, espiritual e social, preservando-se sua liberdade e dignidade ${ }^{7}$.

\section{2 Violência intrafamiliar e seus reflexos no desenvolvimento da criança}

Após tantas agressões físicas e/ou psicológicas vividas em um ambiente hostil a criança sofre muito além, ultrapassando a dor física e a humilhação moral, persistindo esse marco por toda sua vida. Como mencionado acima seus direitos estão assegurados mas não somente a protegem de tanto sofrimento, neste espaço, pois esses impactos negativos se projetam até a vida adulta. (Pereira, Santos \& Williams, 2009) acabam sendo afetadas.

Os sintomas mais frequentes são: falta de motivação, isolamento, ansiedade, comportamento agressivo, depressão, baixo desempenho e evasão escolar, dificuldade de aprendizagem, pouco aproveitamento, repetência e necessidade de educação especial (Brancalhone, Fogo \& Williams, 2004). Os prejuízos podem surgir como danos imediatos: pesadelos repetitivos, raiva, culpa, vergonha, medo do agressor e de pessoa do mesmo sexo que este, quadros fóbico-ansiosos, isolamento social.

Quando os danos aparecem na adolescência pode-se perceber um aumento significativo na incidência de transtornos psiquiátricos, dificuldades para relacionar-se, pensamentos com ideias suicida, fobias mais agudas, níveis intensos de ansiedade, medo, depressão, raiva, culpa, imagens distorcidas do mundo e dificuldade de perceber a realidade, redução na compreensão de papéis complexos e dificuldade para resolver problemas interpessoais (Day, Telles, Zoratto, Azambuja, Machado, Silveira, Debiaggi, Cardoso, Blank, 2003).

A violência contra crianças e adolescentes que vem ocorrendo no País, tem cada vez mais repercussão midiática, porém muitos casos continuam desconhecidos, pois nem todos são notificados por meio de denúncias (Pires \& Miyazaki, 2005). A dificuldade que as pessoas têm para realizar as denúncias torna o contexto ainda mais delicado, pois a criança continua sendo exposta ao agressor. Por esse motivo, a violência pode demorar a ser reconhecida, e para combater a Violência Intrafamiliar Infantil, primeiramente é necessária a

\footnotetext{
${ }^{7}$ ISHIDA, Válter Kenji. Estatuto da criança e do adolescente: doutrina e jurisprudência. 13 ed. São Paulo: Atlas, 2011, p.07.
} 
observação da comunidade e a denuncia imediatamente, seja tanto para assistência social como para a Policia.

Com todos os meios de intervenção através da denúncia, e proteção estatal é necessário essencialmente que os profissionais da área de educação como professores, pedagogos e assistentes sociais, no exercício de suas atividades, estejam envolvidos com o atendimento e a defesa dos direitos da criança. A atuação desses profissionais é fundamental na identificação e prevenção da violência contra criança, pois pode determinar o seu rompimento, impedir que muitos casos continuem acontecendo e interromper o ciclo deste tipo de abuso (Acioli, Lima, Braga, Pimentel, Castro, 2011).

A família tem um papel muito importante para a formação psicossocial da criança, já que o individuo desde sua primeira fase é como um livro branco que ao decorrer de sua trajetória será escrito gradativamente por meio de educação, crenças e culturas transmitidas pelos seus familiares, o que será agora estudado no próximo subtítulo.

\section{A IMPORTÂNCIA DA FAMÍLIA NO DESENVOLVIMENTO EMOCIONAL E SOCIAL DA CRIANÇA E DO ADOLESCENTE}

Contudo, desde que a família deixou de ser o núcleo econômico e de produção para se tornar um espaço para o afeto e o amor, surgiram novos conceitos para ela. Nesse sentido, não há um conceito único para família, já que existem variadas formas de família. Em razão dessa pluralidade de "famílias", a própria Constituição Federal fez a previsão de proteção para esses núcleos, tendo como fundamento, a dignidade da pessoa humana.

Entende-se, então, que família é um núcleo de pessoas que possuem objetivos comuns, que visam a vida em comunidade, através do afeto, da assistência mútua, da solidariedade e do respeito. Existem dois tipos de família:Família consanguínea: aquela na qual o indivíduo nasce, onde há laços genéticos e sanguíneos. Família afetiva: não há laços genéticos, mas de afeto: cônjuge, sogra/sogro.

Segundo Gagliano e Pamplona Filho , após afirmarem que não há uma definição absoluta e infalível para a família, afirmam que ${ }^{8}[\ldots]$ família é o núcleo existencial integrado por pessoas unidas por vínculo socioafetivo, teleologicamente vocacionada a permitir a realização plena dos seus integrantes.

\footnotetext{
${ }^{8}$ GAGLIANO, Pablo Stolze; PAMPLONA FILHO, Rodolfo. Novo curso de direito civil: direito de família - As famílias em perspectiva constitucional. 2.ed. São Paulo: Saraiva, 2012, p. 44.
} 
Segundo Maria Berenice Dias o direito de família regula ${ }^{9}[. .$.$] não só as relações entre$ pais e filhos, mas também entre cônjuges e conviventes, ou seja, a relação das pessoas ligadas por um vínculo de consanguinidade, afinidade ou afetividade.

A família, berço natural da pessoa humana, sempre foi o lugar ideal para a formação e educação dos filhos, além de ser o primeiro agente socializador dos mesmos. A formação da criança, seu crescimento físico, moral e psíquico, depende dos ambientes criados pelos adultos (no lar, os pais), até que adquira sua própria consciência e maturidade. Pode-se dizer que a primeira forma de encontro do homem é com a mãe; entre a mãe e o filho forma-se, então, uma integração por necessidade constitutiva do recém-nascido. O encontro filho-mãe, tem lugar em todas as formas de vinculação, como, por exemplo, troca de olhares, carícias, tom de voz, atos de limpeza, proteção térmica e no ato de agasalhar ${ }^{10}$.

Nesse encontro entre mãe e filho, no recém-nascido se desenvolvem neurônios de diversos setores do cérebro; organizam-se os níveis superiores de integração, ou seja, a orientação das relações humanas e os que regem as regulações neurovegetativas. Ainda, amadurece seus sistemas enzimáticos, forma-se o sistema imunológico através do encontro colisional do organismo com as bactérias que o invadem ${ }^{11}$.

Em virtude de uma boa correspondência entre a dependência da criança e o cuidado instintivo da mãe, surge na criança o sentimento originário de confiança básica na realidade, de acolhimento do ambiente em torno a si. Desse modo, a criança se sente ambientada, acolhida em todo o seu ser, desde o aspecto biológico até a manifestação de sua personalidade. Portanto, as representações que as crianças fazem de si mesmas são, em grande parte, moldadas pelas expectativas dos pais, principalmente da mãe nos primeiros seis meses de vida da criança.

Os valores transmitidos, as contribuições subjetivas dos pais com comportamento da criança constituem um elemento essencial ao desenvolvimento normal. Na verdade, nós transferimos aos outros sentimentos e imagens que são nossos. Assim, o bebê é revestido das características que os pais mais valorizam e é recompensado e amado se tiver um comportamento que reforce essa imagem desejada.

Segundo Sullivan, a criança vem ao mundo através do corpo da mãe; após o parto há uma continuidade sensorial, inicia-se o jogo do tato, do olfato e do som da voz, organiza-se numa dimensão íntima e afetiva. A observação cuidadosa e prolongada de sequências

\footnotetext{
${ }^{9}$ DIAS, Maria Berenice. Manual de direito das famílias. 3.ed. São Paulo: Revista dos Tribunais, 2006

${ }^{10}$ FACHIN, Luiz Edson. Da paternidade: relação biológica e afetiva. Belo Horizonte: Del Rey, 1996.

${ }^{11}$ WINICOTT, D. W. Tudo começa em casa. Trad. Paulo Sandler. São Paulo: Martins Fontes, 1999. 
interativas entre a mãe e o bebê mostra uma sincronia muito grande entre os comportamentos motores e verbais desde os primeiros dias de vida entre mãe e filho, em que uma sucessão de feedbacks proporcionam uma interação vital para o desenvolvimento do bebê $\hat{~}^{12}$.

As mães conferem um enorme significado a tudo aquilo que a criança faz. E o bebê, por sua vez, vai introjetando e reagindo a todas as imagens, às sensações táteis, olfativas e sonoras que surgem ao seu redor e vai criando uma rede de significados, através da qual um conjunto de valores, reforços e proibições irão contribuindo para a formação das experiências que serão o repertório da criança. Após o sexto mês, inicia-se a imagem visual de um rosto. $\mathrm{O}$ bebê começa a perceber a diferença entre um rosto muito familiar e outro que não lhe seja familiar $^{13}$.

Enquanto a mãe, já a partir do sexto mês de vida intrauterina, marca as primeiras impressões sensoriais no bebê, o pai biológico só ingressará no registro paterno quando apresentado pela mãe, no período sensorial, ou seja, em torno do sexto mês de vida, portanto o registro do pai somente chega nove meses depois. Nesse aspecto, o pai está em relação de inferioridade com a mãe.

Segundo Cyrulnik, é importante ressaltar que o nascimento do pai depende, dentre outras coisas, da nomeação feita pela mãe, o que pode não ocorrer, ou seja, o pai pode não nascer. Para ser apresentado ao filho, ele depende da capacidade de nomeação que lhe deve fazer a mulher e, para isso, dispõe do período sensorial ( $6^{\circ}$ ao $8^{\circ}$ mês). Se algum episódio impedir sua nomeação, seja um acidente qualquer, seja porque a mãe lhe negou a entrada, ou mesmo porque a criança não o "adotou", esse momento biológico passa em branco, e a imagem do pai não se estabelece. Em consequência, não se estabelece o elo, não se concretiza a verdadeira vinculação ${ }^{14}$.

A representação do pai permite o acesso ao simbólico, ao pensamento abstrato, à lei. Seu papel triangulador é socializador, justamente pela produção da separação. Quando os papéis parentais se confundem, não mais se estabelecendo o delimitador das fronteiras (limites), a criança percebe dois iguais, o ser e o dever-ser equivalem somente ao ser. Nesse caso, é a ausência da diferença e da lei, e a criança necessita dessa figura "interditadora, proibidora" para ajudá-la a formatar uma base sólida da primeira regra cultural, ou seja, a dos limites ${ }^{15}$.

\footnotetext{
${ }^{12}$ SULLIVAN, Harry Stack. Teoria interpessoal de la psiquiatría. V.1. Buenos Aires: Psique, 1974.

${ }^{13}$ CYRULNIK, B. Sob o signo do afeto. Lisboa: Instituto Piaget, 1989, p. 172

${ }^{14}$ CYRULNIK, B. Sob o signo do afeto. Lisboa: Instituto Piaget, 1989, p. 172

${ }^{15}$ TRINDADE, Jorge. Delinquência juvenil: uma abordagem transdisciplinar. 2. Ed. Porto Alegre: Livraria do Advogado, 1996.
} 
Os pais são parceiros fundamentais no desenvolvimento da criança, cada um com seu papel a desempenhar, no processo de triangulação, tendo o pai seu período delimitado para a entrada na estrutura da vida psíquica de seu filho, como já foi visto anteriormente.

Desse modo, a família, além de ser o meio primário que propicia as primeiras e elementares noções de convivência social, ela é principalmente, também, o meio que possibilitará o desenvolvimento de todas as faculdades físicas, psíquicas, morais e espirituais da criança e do adolescente, no sentido de que, por mais que muitos desses conteúdos (sociais, morais, intelectuais e espirituais) advenham do contato com outras instâncias, a família é a responsável, por assim dizer, pelo cultivo da terra onde as sementes serão lançadas ${ }^{16}$.

De acordo com Adler:

[...] as mais importantes determinantes da estrutura da vida mental, da vida da personalidade, se originam nos primeiros tempos da infância [...] quando tomamos conhecimento das mais vivas recordações da infância de um paciente e sabemos interpretar corretamente essas recordações, podemos construir com grande exatidão os moldes em que se estruturou o seu caráter atual. Para assim concluirmos, fundando-nos no fato de que o indivíduo não se pode desviar da linha de proceder que se formou na sua infância, senão com muita dificuldade ${ }^{17}$.

É evidente que a infância e a adolescência são os momentos ou as fases da vida em que menos alterações drásticas deveriam ocorrer, e onde mais deveria haver o esforço e a manutenção do vínculo afetivo, ou seja, são os momentos em que a certeza do amor deve ser alicerçada a fim de que ambos, criança e adolescente, possam ter um ponto de referência fixo e estável que servirá de apoio para suas futuras relações com o mundo exterior, sendo a estabilidade familiar e a continuação do vínculo afetivo as principais fontes das quais brotarão as raízes físicas, emocionais e sociais que estabilizarão a vida adulta.

Na concepção de Fromm, para a maior parte das crianças antes da exclusivamente o de ser amado, sendo que as crianças até essa idade propriamente não amam, mas correspondem gratamente, alegremente, ao fato de serem amadas ${ }^{18}$.

\section{Considerações Finais}

Pode-se afirmar que, fundamentalmente, o afeto é o elemento básico, nuclear de que necessita a criança em seus primeiros anos de formação, e, paradoxalmente, sendo ele gratuito independente de quaisquer outros fatores. No entanto, em muitas situações, tem-se revelado

\footnotetext{
${ }^{16}$ ADLER, Alfred. A ciência da natureza humana. 6. Ed. São Paulo: Nacional, 1967, p. 18-19.

${ }^{17}$ ADLER, Alfred. A ciência da natureza humana. 6. Ed. São Paulo: Nacional, 1967, p. 18-19.

${ }^{18}$ FROMM, Erich. A arte de amar. Belo Horizonte: Itatiaia, 1991, p. 53-54.
} 
como um raro bem, engendrando, pois uma violação a que se refere ao direito ao carinho, o direito ao amor.

Nesse contexto, não é exagero afirmar que a principal responsável pela criação e pela proteção do infante, desde a infância à adolescência é, sem dúvida, a família, sendo ela indispensável à iniciação das crianças na cultura, nos valores e nas normas de sua sociedade, devendo, porém, o Estado lhe dar o devido suporte para que possa exercer de forma adequada o seu papel.

Para um desenvolvimento completo e harmonioso de sua personalidade, a criança deve crescer num ambiente familiar adequado, ou seja, numa atmosfera de felicidade, amor e compreensão. Ocorre que nem sempre as famílias estabelecem relações estáveis e de reciprocidade com suas crianças. Nesse caso, os infantes, inevitavelmente, serão inseridos no meio social com distúrbios de comportamento. A função da família em relação ao direito da criança e do adolescente está claramente expressa na lei. O Estatuto da Criança e do Adolescente, em seu artigo 19, reafirma o direito à convivência familiar e comunitária, já enunciado no art. 227 da Constituição Federal, dispondo que: "toda criança ou adolescente tem direito a ser criado e educado no seio de sua família (...)”. o que por outro lado, não descompromete a sociedade de proteger e garantir os direitos e garantias individuais no começo da vida, investindo na erradicação da pobreza e na política da parentalidade.

As crianças necessitam dos pais para o desenvolvimento do afeto, da colaboração e do senso de pertencimento em comunidade. Quando se propõe políticas públicas para a melhor infância, primando pelo começo da vida, significa dizer, da responsabilidade que a sociedade tem com a condição humana da criança. Ao não olhar para infância, nega-se o direito fundamental a vida. A pobreza extrema é uma das piores violações de direitos humanos que uma criança pode sofrer, pois além dos tantos malefícios materiais, sociais que causa, suprimi com o direito a felicidade, ao não poder brincar e sonhar com um mundo de oportunidades.

\title{
THE PARTICIPATION OF CHILDREN SINCE THE FIRST CHILDHOOD IN ACTIONS THAT SEEK TO FACE INTRA-FAMILY VIOLENCE AND THEIR CONSEQUENCES AS A FUNDAMENTAL STRATEGY FOR THE CONSTRUCTION OF AN EFFECTIVE POLICY
}

\begin{abstract}
This article aims to analyze the law 13,257, of 8 March 2016 providing for public policies for early childhood based on the National Plan for the First Childhood, which proposes broad and coordinated actions of promotion and realization of rights child up to six years old in the next twelve years. Among its various objectives and full protection goals the family is child participation from early childhood in actions that aim to face domestic violence and its
\end{abstract}


consequences as a key strategy for building an effective policy. As text construction mechanisms used the method of approach the hypothetical -deductive, as the monographic procedure method and technique of literature review.

Keywords: child and adolescent, family violence, gender.

\section{Referências}

AZEVEDO, Maria Amélia e GERRA, Viviane Nogueira de Azevedo. Mania de bater: a punição corporal doméstica de crianças e adolescentes no Brasil. São Paulo: Editora iglu, 2001.

ADLER, Alfred. A ciência da natureza humana. 6. Ed. São Paulo: Nacional, 1967.

Acioli, R. M. L; Lima, M. L. C.,Braga, M. C., Pimentel, F. C. \& Castro, S. G. (2011).

Violência intrafamiliar contra crianças e adolescentes: identificação, manejo e conhecimento da rede de referência por fonoaudiólogo em serviços públicos de saúde. Rev. Bras. Saúde Mater. Infant.[online]. vol.11, p. 21-28.

CYRULNIK, B. Sob o signo do afeto. Lisboa: Instituto Piaget, 1989, p. 172

CUSTÓDIO, André Viana. Direito da Criança e do Adolescente. Criciúma, SC: UNESC, 2009.

DIAS, Maria Berenice. Manual de direito das famílias. 3.ed. São Paulo: Revista dos Tribunais, 2006.

Day, V. P., Telles, L. E. B., Zoratto,P. H., Azambuja, M. R. F., Machado, D. A., Silveira, M. B., Debiaggi, M. Reis, M. G., Cardoso, R. G. \&Blank, P. (2003). Violência doméstica e suas diferentes manifestações. Rev. psiquiatr. Rio Gd. Sul [online]. vol.25, p. 9-21.

GAGLIANO, Pablo Stolze; PAMPLONA FILHO, Rodolfo. Novo curso de direito civil: direito de família - As famílias em perspectiva constitucional. 2.ed. São Paulo: Saraiva, 2012, p. 44.

FACHIN, Luiz Edson. Da paternidade: relação biológica e afetiva. Belo Horizonte: Del Rey, 1996. 
ISHIDA, Válter Kenji. Estatuto da criança e do adolescente: doutrina e jurisprudência. 13 ed. São Paulo: Atlas, 2011.

Pereira, P. C.,Santos, A.B. \& Williams, L.C.A.(2009). Desempenho escolar da criança vitimizada encaminhada ao fórum judicial. Psicologia: Teoria e pesquisa, 19-28.

Brancalhone, P.G., Fogo, J.C. \& Williams, L.C.A. (2004). Crianças expostas a violência conjugal: avaliação do desempenho acadêmico. Psicologia:teoria e pesquisa, 113-117.

Pires, A. L. D.\& Miyazaki, M. C. O. S. (2005) Maus-tratos contra crianças e adolescentes: revisão da literatura para profissionais da saúde. ArqCiênc e Saúde, p. 7.

WINICOTT, D. W. Tudo começa em casa. Trad. Paulo Sandler. São Paulo: Martins Fontes, 1999

SULLIVAN, Harry Stack. Teoria interpessoal de la psiquiatría. V.1. Buenos Aires: Psique, 1974.

TRINDADE, Jorge. Delinquência juvenil: uma abordagem transdisciplinar. 2. Ed. Porto Alegre: Livraria do Advogado, 1996.

\section{Sobre os autores:}

Rosane Teresinha Carvalho Porto é Doutora em Direito pela UNISC. Mestre em Direito na área de concentração: Políticas Públicas de Inclusão Social com bolsa da Coordenação de Aperfeiçoamento de Pessoal de Nível Superior - CAPES. Policial Militar. Professora de Direito da Infância e da Juventude e de Criminologia , na UNISC, Subcoordenadora do curso de direito UNISC / Sobradinho. Editora Adjunta da Revista do Direito/PPGD. Estuda temáticas voltadas a criança e adolescente, violência, criminologia, gênero e Justiça Restaurativa. Integrante do Grupo Direito, Cidadania e Políticas Públicas coordenado pela Professora Pós-Doutora Marli Marlene Moraes da Costa. Assessora científica do MACKPESQUISA. Facilitadora de Justiça Restaurativa em formação pelo Tribunal de Justiça do RS, atuando no CEJUSC/RS. E-mail: rosaneporto@unisc.br

Fabiano Rodrigo Dupont é Mestre em Direito pela Universidade de Santa Cruz do Sul UNISC, na linha de pesquisa Políticas Públicas. Graduado em Direito pela Universidade de Santa Cruz do Sul - UNISC. Integrante dos grupos de pesquisa "Gestão Local e Políticas Públicas", coordenado pelo Prof. Dr. Ricardo Hermany, e "Políticas Públicas", junto à Escola Miguel Arraes / Fundação João Mangabeira - DF. E-mail: fabianodupont@ hotmail.com 